\title{
The molecular pathophysiology of vascular anomalies: Genomic research
}

\author{
Jong Seong Kim ${ }^{1}$, Su-Kyeong Hwang ${ }^{2}$, Ho Yun Chung ${ }^{1,3}$ \\ Departments of ${ }^{1}$ Plastic and Reconstructive Surgery and ${ }^{2}$ Pediatrics, ${ }^{3}$ Cell \& Matrix Research Institute, School of Medicine, Kyungpook \\ National University, Daegu, Korea
}

\begin{abstract}
Vascular anomalies are congenital localized abnormalities that result from improper development and maintenance of the vasculature. The lesions of vascular anomalies vary in location, type, and clinical severity of the phenotype, and the current treatment options are often unsatisfactory. Most vascular anomalies are sporadic, but patterns of inheritance have been noted in some cases, making genetic analysis relevant. Developments in the field of genomics, including next-generation sequencing, have provided novel insights into the genetic and molecular pathophysiological mechanisms underlying vascular anomalies. These insights may pave the way for new approaches to molecular diagnosis and potential disease-specific therapies. This article provides an introduction to genetic testing for vascular anomalies and presents a brief summary of the etiology and genetics of vascular anomalies.
\end{abstract}

Keywords Vascular anomalies / Genomic research / DNA sequencing / Next generation sequencing / Signaling pathway
Correspondence: Ho Yun Chung Department of Plastic and Reconstructive Surgery, School of Medicine, Kyungpook National University, 130 Dongdeok-ro, Junggu, Daegu 41944, Korea Tel: +82-53-420-5692 Fax: +82-53-425-3879 E-mail: hy-chung@knu.ac.kr

This work was supported by the National Research Foundation of Korea (NRF) grant funded by the Korea government (MSIT) (No. 2020R1A2C2009496).

Received: April 6, $2020 \bullet$ Revised: April 30, 2020 - Accepted: April 30, 2020

pISSN: 2234-6163 • elSSN: 2234-6171 • https://doi.org/10.5999/aps.2020.00591 • Arch Plast Surg 2020;47:203-208

\section{INTRODUCTION}

The clinicopathological classification of vascular anomalies, which was first proposed by Mulliken and Glowacki in 1982 [1], has continued to be a basic standard. The classification of these anomalies into two broad categories-tumors and vascular malformations-was the basis of the 2018 classification proposed by the International Society for the Study of Vascular Anomalies (ISSVA). However, there are still many limitations of pathophysiological analyses on the basis of clinical and histological findings [2-4]. Since recent studies have identified many genes potentially linked to vascular anomalies, several pathophysiological analyses based on these genes have been conducted, and potential new treatments have also been proposed. Since the 1990s, the genetic basis for vascular anomalies has been eluci- dated, and as a result, mutations associated with numerous types of lesions have been reported over the past few years [3]. Recent developments in sequencing technologies have opened new horizons in terms of genomic studies, and research in this field is actively expanding [5]. This article presents an introduction to genetic testing for vascular anomalies and a brief summary of the etiology and genetics of vascular anomalies.

\section{GENETIC TESTS FOR VASCULAR ANOMALIES}

In the past few decades, remarkable and unexpected advances in genetic testing have been made. The completion of the Human Genome Project in 2003 was followed by a veritable flood of discoveries regarding the genetic basis of various diseases [6]. Even- 
tually, patients' genomes will be sequenced to identify genetic diseases, to analyze the causes of complex multifactorial diseases, and to predict the best treatment and prognosis for each individual.

There are two major classes of genetic variations: copy number variations (CNVs) and single-nucleotide variants (SNVs). A $\mathrm{CNV}$ is defined as a change in length of 1,000 or more base sequences. Genome-wide CNVs can be detected using a chromosomal microarray (CMA) with high resolution. SNVs take place when a single nucleotide (e.g., A, T, C, or G) is altered in the DNA sequence. SNVs are the most frequent genomic variations.

Sequencing refers to reading the DNA base sequence containing genetic information in order. DNA sequencing can be broadly divided into Sanger sequencing and next-generation sequencing (NGS) [7]. The Sanger method involves sequencing single strands of DNA, whereas in NGS, one long DNA strand is cut into millions of strands, and then genes are amplified and sequenced at once $[7,8]$. NGS is composed of four basic steps. The first step is library preparation, in which extracted DNA is cut into millions of pieces randomly and then adapters are attached to the 5' and 3' ends of DNA for further polymerase chain reaction (PCR). Second, in the cluster generation step, each of the millions of DNA fragments is amplified through PCR to create clonal clusters. Third, in the sequencing step, complementary nucleotides are generated by DNA polymerase from the DNA strand cluster and the nucleotide type is identified with fluorescence. Fourth, in the data analysis step, the sequence data of millions of short reads are arranged using the reference genome and sequencing results are obtained through bioinformatics. Sanger sequencing reads hundreds of nucleotide sequences in detail, whereas NGS can quickly identify sequences across genomes at a low cost. The general category of NGS includes whole exome sequencing (WES), targeted gene panel sequencing (TS), and whole genome sequencing (WGS).

Applicable genetic testing methods for vascular anomalies are Sanger sequencing for a defined phenotype with a monogenic disorder, CMA, TS, WES, and WGS. The testing method should be carefully chosen according to the purpose of testing. Usually, CNVs are analyzed by CMA or WGS, whereas SNVs and small insertions/deletions are more suitable for analysis by sequencing, WES, or WGS. Genetic testing can follow an orderly progression if the diagnosis remains unclear.

Mutations can be classified into germline mutations and somatic mutations. Germline mutations pass from the parent to the offspring through germ cells, and can therefore be found in almost every cell in an individual. Somatic mutations occur only in a subgroup of cells (excluding germ cells) in an individual. Therefore, these mutations are not transmitted to the next generation. Instead, they are only transmitted to the offspring of the affected cells, giving rise to somatic mosaicism, which plays a major role in the development of vascular lesions. Somatic mutations can cause disease, as exemplified by cancer, where cells acquire somatic mutations and develop into tumors.

Although familial inheritance has also been reported, most vascular anomalies are sporadic. Germline mutations can be tested using blood, buccal mucosal cells, or lesion tissue samples; however, somatic mutations can only be found in lesion tissue samples. NGS has proven to be a valuable tool for discovering somatic mutations $[9,10]$.

\section{GENETICS OF VASCULAR ANOMALIES}

The causal genes of vascular anomalies known to date are well organized in the ISSVA classification of vascular anomalies (c2018 ISSVA, available from: issva.org/classification) [11].

\section{Vascular tumors}

\section{Infantile hemangioma}

Infantile hemangioma (IH) arises from the proliferation of endothelial cells (ECs). Two main proposals have been made regarding the origins of ECs in $\mathrm{IH}$ : embolic placental angioblasts, which share placental markers (glucose transporter protein 1 [GLUT1], Fc $\gamma$ receptor II, Lewis Y antigen, and merosin), and endothelial progenitor cells $\left(\mathrm{CD} 133^{+} / \mathrm{CD} 34^{+}\right.$circulating progenitor cells and stem cells) $[12,13]$. Vascular endothelial growth factor (VEGF)-A signaling is associated with IH. In the ECs in $\mathrm{IH}$, the formation of $\mathrm{IH}$ has been shown to be caused by changes in the VEGF-A signaling pathway that are related to missense mutations in the genes encoding VEGFR2 (KDR) and TEM8 (ANTXR1) [14,15].

\section{Congenital hemangioma}

There are three types of congenital hemangioma $(\mathrm{CH})$ that appear fully formed at birth: non-involuting $\mathrm{CH}$, partially involuting $\mathrm{CH}$, and rapidly involuting $\mathrm{CH}[15,16]$. They are all GLUT1-negative. It has been reported that there is a mutation at the glutamine 209 (Gln209) position in GNAQ or GNA11, and the Gln209 missense mutation is known to activate GTPdependent signaling, which leads to the constitutive activation of MAPK and/or YAP signaling [17].

\section{Pyogenic granuloma}

Pyogenic granuloma (PG) may be isolated or associated with a capillary malformation (CM). It has been reported that PGs associated with CM (secondary PGs) show a somatic GNAQ mutation reflecting an origin from CM cells. Furthermore, BRAF 
somatic mutations were found in eight of 10 secondary PGs and NRAS mutations in one of 10 . However, isolated PGs were associated with BRAF (four of 25) or KRAS (one of 25) mutations [18]. A somatic activating GNA14 mutation has been reported in one case and a GNA11 mutation in two cases [19].

\section{Kaposiform hemangioendothelioma}

Kaposiform hemangioendothelioma (KHE) is usually present at birth and is typically diagnosed in infancy or early childhood. The incidence of the Kasabach-Merritt phenomenon has been estimated at $42 \%$ to $71 \%$ in KHE [20]. GNA14 mutations were found in one of three KHE specimens and one of four closely related tufted angiomas [19].

\section{Vascular malformations Capillary malformation}

CM is the most common type of vascular malformation [21]. GNAQ mutations were found in $80 \%-90 \%$ of cases with a sporadic or syndromic (Sturge-Weber syndrome) etiology [22]. GNA11 mutations were identified in three of eight specimens with diffuse CM and overgrowth of an extremity [23]. The GNAQ mutations in CM primarily present in ECs [24]. Atypical CM may co-occur with arteriovenous malformation (AVM) in a single patient. This entity, which is referred to as CM-AVM, can be subdivided into CM-AVM1 and CM-AVM2. CM-AVM1 is inherited in an autosomal dominant pattern and is caused by a RASA1 mutation [25]. One-third of patients with CM-AVM1 have fast-flow lesions; in contrast, the risk of fast-flow malformations is lower in CM-AVM2, which is caused by a loss-of-function mutation in EPHB4 [26].

\section{Lymphatic malformations}

Lymphatic malformations (LMs) are sporadic slow-flow lesions that are composed of multiple cystic structures, which can be macroscopic, microscopic or combined [27]. PIK3CA mutations were found in 16 of 17 specimens. Mutations in the PIK$3 C A$ gene can enhance the ability of its protein product to bind to the cell membrane or activate its kinase, which results in activation of the AKT/mTOR signaling pathway [28,29]. Rapamycin (sirolimus), which is well known as an mTOR inhibitor, has shown good efficacy and a favorable safety profile when used in patients [10]. Primary lymphedema is a type of vascular malformation that can be hereditary. Several mutations (VEGFR3/ FLT-4, FOXC2, SOX18, CCBE1, etc.) have been identified in patients with primary lymphedema [15].

\section{Venous malformations}

Venous malformations (VMs) are usually sporadic, but can be familial [30]. Cutaneomucosal autosomal dominant VM was found to be caused by TIE2 mutations, which were found in 80 of 130 specimens of sporadic VMs. Activating somatic mutations of PIK3CA have also been identified in sporadic VMs that lacked TEK/TIE2 mutations [3,15,31]. Verrucous VMs associated with the MAP3K3 mutation are hyperkeratotic abnormalities that affect the skin of limbs [32]. Glomuvenous malformation (GVM) is an autosomal dominant disease in which several small lesions are caused by germline or somatic loss-of-function mutations in glomulin (GLMN) [33]. GVMs have reported as requiring somatic second-hit mutations to trigger disease onset; the first mutation is inherited in an autosomal dominant manner, while the second mutation is acquired. Blue rubber bleb nevus syndrome, which is a non-hereditary condition, presents as multifocal VMs. This syndrome is associated with TIE2 mutations [34]. Cerebral cavernous malformations (CCMs) are characterized by enlarged capillary cavities in the central nervous system. In 9\% of CCM patients, cutaneous lesions are also found. CCMs, which are associated with mutations in CCM1/ KRIT1, CCM2/malcavernin, and CCM3/PDCD10, can be sporadic or familial $[5,35]$.

\section{Arteriovenous malformations}

AVMs are anomalous connections between arteries and veins through a nidus or fistula, bypassing high-resistance capillary beds [36]. AVMs occur sporadically, and are associated with a mutation in the MAP2K1 gene [37]. Inherited AVMs can occur in the context of other conditions, such as hereditary hemorrhagic telangiectasia ( $\mathrm{HHT}$ ), and combined diseases such as CM-AVM (see CM) and Parkes Weber syndrome [10,15,24].

\section{Hereditary hemorrhagic telangiectasia}

HHT is an autosomal dominant vascular dysplasia that can cause epistaxis, mucocutaneous telangiectasias, and/or visceral AVMs. Ninety percent of HHT cases are associated with a lossof-function mutation of one of three identified genes. HHT1 is associated with mutations in endoglin (ENG), a co-receptor for activin-like receptor; HHT2 with mutations in activin receptorlike kinase 1 (ACVRL1); and juvenile polyposis/HHT syndrome with mutations in $M A D H 4$, which encodes the downstream effector SMAD4. HHT is associated with germline mutations in genes involved in the TGF- $\beta$ /BMP signaling pathway $[5,38,39]$.

\section{Vascular malformations associated with other anomalies}

Vascular malformations are one of the major components in various syndromes that cause enlargement of soft tissues or bones. Klippel-Trenaunay syndrome (KTS) presents with a 
classic triad of port-wine stains, asymmetric extremity overgrowth, and underlying VMs or LMs [40,41]. In 19 of 21 KTS patients, PIK3CA mutations were found to play a role in the pathogenesis of the condition [42]. Macrocephaly-CM usually causes neurological abnormalities, and patients typically have $\mathrm{CM}$ on the upper lip, back, and/or limbs. These patients also have PIK3CA mutations [43]. CLOVES syndrome is characterized by congenital lipomatosis, overgrowth, vascular malformations, epidermal nevi, and skeletal anomalies. Mutations in PIK$3 C A$ were identified in 36 of 38 patients [44]. Proteus syndrome, which features asymmetric growth of skeletal and connective tissue, cerebriform nevi of the hands or feet, epidermal nevi, and underlying vascular malformations, results from a somatic activating mutation in AKT1 [45]. Maffucci syndrome features several enchondromas and soft-tissue VMs. This condition results from somatic mutations of isocitrate dehydrogenase (IDH), with $98 \%$ of cases caused by IDH1 mutations and $2 \%$ by $\mathrm{IDH} 2$ mutations [46].

\section{ABNORMAL SIGNALING PATHWAYS IN VASCULARANOMALIES}

These genetic mutations directly change the activities of intracellular signaling pathways, thereby influencing various downstream actions. The pathways most involved in vascular anomalies are the $\mathrm{PI} 3 \mathrm{~K} / \mathrm{AKT} / \mathrm{mTOR}$ and RAS/MAPK signaling pathways. Another important signaling mechanism is the TGF- $\beta / S M A D$ signaling pathway, which plays a role in HHT (Fig. 1).

Fig. 1. Mutations and signaling pathways in vascular anomalies

Mutations in vascular abnormalities affect genes involved in tyrosine kinase signaling via the RAS or PIK3CA pathways. This figure is a schematic diagram of key genetic mutations related to signal transduction and vascular malformations in endothelial cells. Proteins mutated in other vascular disorders are indicated. Mutations in GNAQ/GNA11/GNA14, RASA1, and KRIT lead to constitutive activation of RAS/RAF/MEK/ERK signaling. Mutations in TIE2/TEK lead to permanent activation of the PIK3CA/AKT/mTOR pathway. AVM, arteriovenous malformation; BAVM, brain arteriovenous malformation; BRBNS, blue rubber bleb nevus syndrome; BRRS, Bannayan-Riley-Ruvalcaba syndrome; CCM, cerebral cavernous malformation; $\mathrm{CH}$, congenital hemangioma; CLAPOS, CLAPO syndrome; CLM, cystic lymphatic malformation; CLOVESS, CLOVES syndrome; CM, capillary malformation; CommonVM, common venous malformation; CMAVM, capillary malformation-arteriovenous malformation 1,2; CMOM, capillary malformation of macrocephaly; CVM, cutaneomucosal venous malformation; $\mathrm{CH} D C M$, diffuse capillary malformation; EAVM, extracranial arteriovenous malformation; FIL, facial infiltrating lipomatosis; FAVA, fibroadipose vascular anomaly; VMCM, Familial venous malformation cutaneous and mucosal; HHT, hereditary hemorrhagic telangiectasia; IM, infantile myofibroma; JPHT, juvenile polyposis hemorrhagic telangiectasia; KHE, kaposiform hemangioendothelioma; KTS, Klippel-Trenaunay syndrome; LCMCNPLOG, limb capillary malformation with congenital nonprogressive limb overgrowth; MD, Milroy's disease; MCM, megalencephaly capillary malformation; NSCM, non-syndromic capillary malformation; PL, primary lymphedema; PS, Proteus syndrome; PTHS, PTEN hamartoma syndrome; PG, pyogenic granuloma; PWS, Parkes Weber syndrome; PWSWM, port wine stain with macrocheilia; SVAM, spinal arteriovenous malformation; SWS, Surge-Weber syndrome; TA, tufted angioma; VM, venous malformation; WM, verrucous venous malformation.

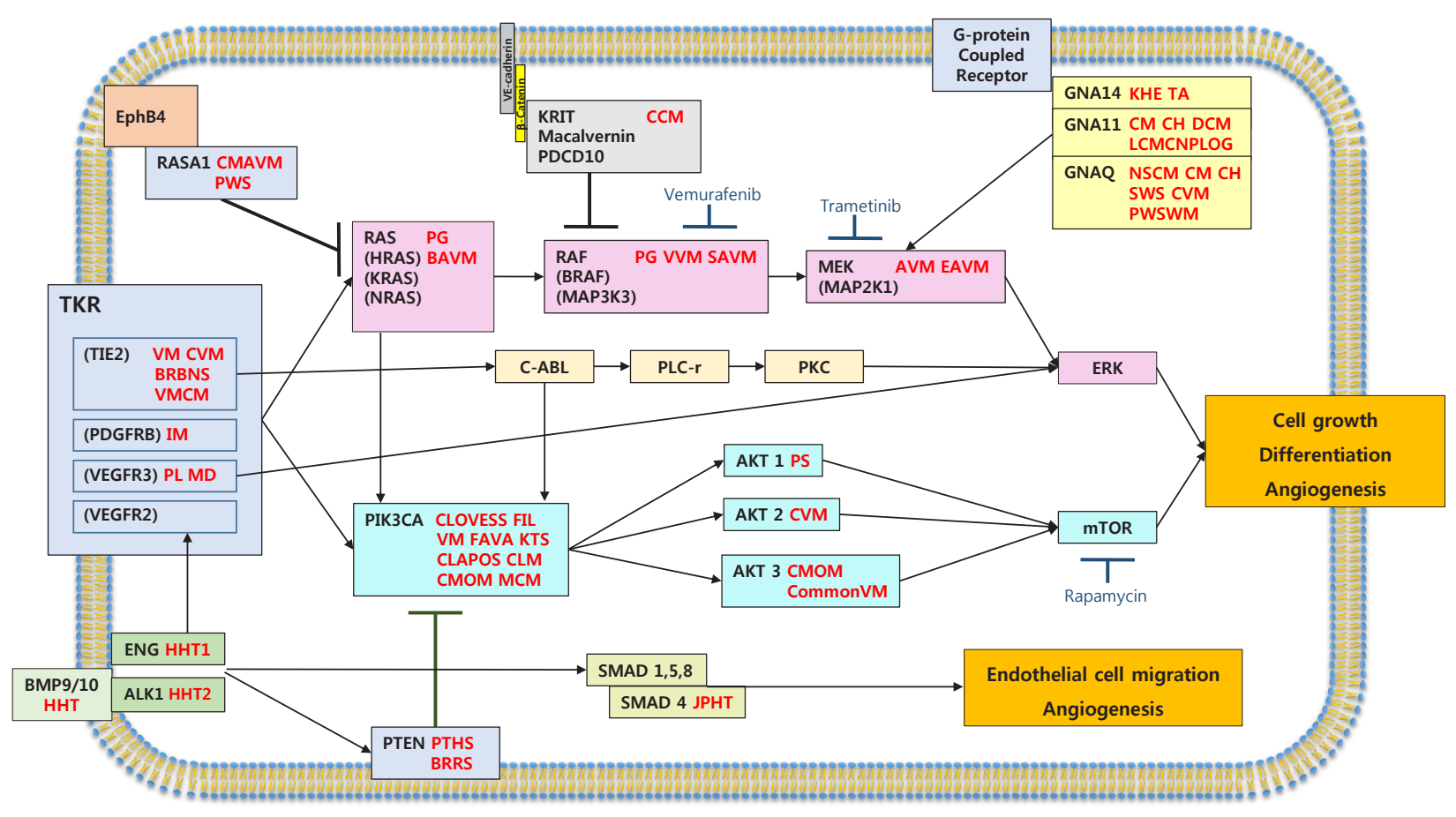




\section{CONCLUSIONS}

Advances in DNA sequencing have yielded extensive knowledge regarding the etiological molecular mechanisms involved in the development of vascular anomalies. NGS is a very effective method of analyzing germline and somatic mutations of vascular anomalies, which have various phenotypes, and their associated dysfunctions. An important point to be emphasized is that somatic mutations and their mechanisms for vascular anomalies, which mainly are sporadic and unifocal, should be further studied in the future. Although many downstream effects remain unknown, it is clear that normalization of the affected signaling pathways is an important target for treatment. Mutation-specific targeted therapies are also being studied, which may result in a paradigm shift in therapeutic approaches to vascular anomalies. Further research into the cellular effects of mutations is expected to yield insights into the underlying pathophysiology that will enable new therapies to be developed.

\section{NOTES}

\section{Conflict of interest}

No potential conflict of interest relevant to this article was reported.

\section{Author contribution}

Conceptualization: JS Kim, SK Hwang, HY Chung. Data curation: JS Kim, SK Hwang, HY Chung. Formal analysis: HY Chung. Funding acquisition: HY Chung. Methodology: HY Chung. Project administration: HY Chung. Visualization: JS Kim, HY Chung. Writing - original draft: JS Kim, HY Chung. Writing - review \& editing: JS Kim, SK Hwang, HY Chung.

\section{ORCID}

Jong Seong Kim

Su-Kyeong Hwang

https://orcid.org/0000-0002-4725-9277

Ho Yun Chung

https://orcid.org/0000-0001-8294-7094

https://orcid.org/0000-0001-7359-3044

\section{REFERENCES}

1. Mulliken JB, Glowacki J. Hemangiomas and vascular malformations in infants and children: a classification based on endothelial characteristics. Plast Reconstr Surg 1982;69:41222.

2. Mulliken JB, Burrows PE, Fishman DJ. Mulliken and Young's vascular anomalies: hemangiomas and malformations. 2nd ed. New York: Oxford University Press; 2013.

3. Greene AK, Goss JA. Vascular anomalies: from a clinicohisto- logic to a genetic framework. Plast Reconstr Surg 2018;141: 709e-717e.

4. Lee JW, Chung HY. Vascular anomalies of the head and neck: current overview. Arch Craniofac Surg 2018;19:2437.

5. Queisser A, Boon LM, Vikkula M. Etiology and genetics of congenital vascular lesions. Otolaryngol Clin North Am 2018;51:41-53.

6. Collins FS, Morgan M, Patrinos A. The Human Genome Project: lessons from large-scale biology. Science 2003;300: 286-90.

7. Sohn J. Next generation sequencing and anti-cancer therapy. J Korean Med Assoc 2019;62:119-29.

8. Koboldt DC, Steinberg KM, Larson DE, et al. The nextgeneration sequencing revolution and its impact on genomics. Cell 2013;155:27-38.

9. Wetzel-Strong SE, Detter MR, Marchuk DA. The pathobiology of vascular malformations: insights from human and model organism genetics. J Pathol 2017;241:281-93.

10. Adams DM. Practical genetic and biologic therapeutic considerations in vascular anomalies. Tech Vasc Interv Radiol 2019;22:100629.

11. International Society for the Study of Vascular Anomalies (ISSVA). ISSVA classification of vascular anomalies [Internet]. Milwaukee, WI: ISSVA; c2018 [cited 2020 May 11]. Available from: issva.org/classification.

12. North PE, Waner M, Brodsky MC. Are infantile hemangiomas of placental origin? Ophthalmology 2002;109:633-4.

13. Khan ZA, Boscolo E, Picard A, et al. Multipotential stem cells recapitulate human infantile hemangioma in immunodeficient mice. Version 2.J Clin Invest 2008;118:2592-9.

14. Jinnin M, Medici D, Park L, et al. Suppressed NFAT-dependent VEGFR1 expression and constitutive VEGFR2 signaling in infantile hemangioma. Nat Med 2008;14:1236-46.

15. Uebelhoer M, Boon LM, Vikkula M. Vascular anomalies: from genetics toward models for therapeutic trials. Cold Spring Harb Perspect Med 2012;2:a009688.

16. Nasseri E, Piram M, McCuaig CC, et al. Partially involuting congenital hemangiomas: a report of 8 cases and review of the literature. J Am Acad Dermatol 2014;70:75-9.

17. Ayturk UM, Couto JA, Hann S, et al. Somatic activating mutations in GNAQ and GNA11 are associated with congenital hemangioma. Am J Hum Genet 2016;98:789-95.

18. Groesser L, Peterhof E, Evert M, et al. BRAF and RAS mutations in sporadic and secondary pyogenic granuloma. J Invest Dermatol 2016;136:481-6.

19. Lim YH, Bacchiocchi A, Qiu J, et al. GNA14 somatic mutation causes congenital and sporadic vascular tumors by 
MAPK activation. Am J Hum Genet 2016;99:443-50.

20. Ji Y, Chen S, Yang K, et al. Kaposiform hemangioendothelioma: current knowledge and future perspectives. Orphanet J Rare Dis 2020;15:39.

21. Lee JW, Chung HY. Capillary malformations (Portwine Stains) of the head and neck: natural history, investigations, laser, and surgical management. Otolaryngol Clin North Am 2018;51:197-211.

22. Shirley MD, Tang H, Gallione CJ, et al. Sturge-Weber syndrome and port-wine stains caused by somatic mutation in GNAQ. N Engl J Med 2013;368:1971-9.

23. Couto JA, Ayturk UM, Konczyk DJ, et al. A somatic GNA11 mutation is associated with extremity capillary malformation and overgrowth. Angiogenesis 2017;20:303-6.

24. Couto JA, Huang L, Vivero MP, et al. Endothelial cells from capillary malformations are enriched for somatic GNAQ mutations. Plast Reconstr Surg 2016;137:77e-82e.

25. Eerola I, Boon LM, Mulliken JB, et al. Capillary malformation-arteriovenous malformation, a new clinical and genetic disorder caused by RASA1 mutations. Am J Hum Genet 2003;73:1240-9.

26. Amyere M, Revencu N, Helaers R, et al. Germline loss-offunction mutations in EPHB4 cause a second form of Capillary Malformation-Arteriovenous Malformation (CMAVM2) deregulating RAS-MAPK signaling. Circulation 2017;136:1037-48.

27. Cho BC, Kim JB, Lee JW, et al. Cervicofacial lymphatic malformations: a retrospective review of 40 cases. Arch Plast Surg 2016;43:10-8.

28. Boscolo E, Coma S, Luks VL, et al. AKT hyper-phosphorylation associated with PI3K mutations in lymphatic endothelial cells from a patient with lymphatic malformation. Angiogenesis 2015;18:151-62.

29. Osborn AJ, Dickie P, Neilson DE, et al. Activating PIK3CA alleles and lymphangiogenic phenotype of lymphatic endothelial cells isolated from lymphatic malformations. Hum Mol Genet 2015;24:926-38.

30. Park H, Kim JS, Park H, et al. Venous malformations of the head and neck: a retrospective review of 82 cases. Arch Plast Surg 2019;46:23-33.

31. Uebelhoer M, Natynki M, Kangas J, et al. Venous malformation-causative TIE2 mutations mediate an AKT-dependent decrease in PDGFB. Hum Mol Genet 2013;22:3438-48.

32. Couto JA, Vivero MP, Kozakewich HP, et al. A somatic MAP3K3 mutation is associated with verrucous venous malformation. Am J Hum Genet 2015;96:480-6.
33. Brouillard P, Boon LM, Mulliken JB, et al. Mutations in a novel factor, glomulin, are responsible for glomuvenous malformations ("glomangiomas"). Am J Hum Genet 2002; 70:866-74.

34. Soblet J, Kangas J, Natynki M, et al. Blue Rubber Bleb Nevus (BRBN) syndrome is caused by somatic TEK (TIE2) mutations. J Invest Dermatol 2017;137:207-16.

35. Cavalcanti DD, Kalani MY, Martirosyan NL, et al. Cerebral cavernous malformations: from genes to proteins to disease. J Neurosurg 2012;116:122-32.

36. Kim JB, Lee JW, Choi KY, et al. Clinical characteristics of arteriovenous malformations of the head and neck. Dermatol Surg 2017;43:526-33.

37. Couto JA, Huang AY, Konczyk DJ, et al. Somatic MAP2K1 mutations are associated with extracranial arteriovenous malformation. Am J Hum Genet 2017;100:546-54.

38. Bayrak-Toydemir P, McDonald J, Akarsu N, et al. A fourth locus for hereditary hemorrhagic telangiectasia maps to chromosome 7. Am J Med Genet A 2006;140:2155-62.

39. Cole SG, Begbie ME, Wallace GM, et al. A new locus for hereditary haemorrhagic telangiectasia (HHT3) maps to chromosome 5. J Med Genet 2005;42:577-82.

40. Sung HM, Chung HY, Lee SJ, et al. Clinical experience of the Klippel-Trenaunay syndrome. Arch Plast Surg 2015;42:5528.

41. Jacob AG, Driscoll DJ, Shaughnessy WJ, et al. Klippel-Trenaunay syndrome: spectrum and management. Mayo Clin Proc 1998;73:28-36.

42. Luks VL, Kamitaki N, Vivero MP, et al. Lymphatic and other vascular malformative/overgrowth disorders are caused by somatic mutations in PIK3CA. J Pediatr 2015;166:104854.

43. Mirzaa GM, Riviere JB, Dobyns WB. Megalencephaly syndromes and activating mutations in the PI3K-AKT pathway: MPPH and MCAP. Am J Med Genet C Semin Med Genet 2013;163C:122-30.

44. Kurek KC, Luks VL, Ayturk UM, et al. Somatic mosaic activating mutations in PIK3CA cause CLOVES syndrome. Am J Hum Genet 2012;90:1108-15.

45. Lindhurst MJ, Sapp JC, Teer JK, et al. A mosaic activating mutation in AKT1 associated with the Proteus syndrome. N Engl J Med 2011;365:611-9.

46. Amary MF, Damato S, Halai D, et al. Ollier disease and Maffucci syndrome are caused by somatic mosaic mutations of IDH1 and IDH2. Nat Genet 2011;43:1262-5. 